than the emanations from a neighbouring water-closet. The door of this was generally left ajar, and the place had, as usual, but a single window for ventilation. A somewhat similar case occurred with a woman in child-bed, mild fever being the result.

These are but samples of much more that could be given. It is not safe to believe that the first rudiments of sanitary science have been sufficiently taught. There are many people who either do not know them, or, what is even more frequent, do not attend to them and caryy out their teachings. Cesspools are not yet things of the past. Refuse-heaps, manurc-heaps, offensive trades, crowded collections of animals, yes, even sometimes of human animals, are not yet swept away. They are sometimes hid round colnel's, and in nooks, towards which the eyes of inspectors do not always seem to bend. I have seen nuisances, years ago complained of and supposed to be removed, still existing, and nearly in the original state; sanitary ovils, long pointed out, not yet remedied; nuisances, which the arm of the liw ought to have long ago reached, but which it seems to have no power to interfere with. In short, considering the talk and stir. about sanitary matters which has gone on for these thirty years, and allowing for good things done and arrnugements made, it looks as if some localities were not much the better for it all. It mav be that lealth officer's do not find themselves sufficiently free to do their whole duty. It is certain that some of them are very insufficiently paid. And it is also certain, that sanitary measures are not yet supported by the roice and vote of the whole community, and that both the knowledge and the disposition to do these things rightly are not yet possessed by all.

W. E. C. Nourse, F.R.C.S.

\title{
On the Past and Present Prevalence of several Dis- eases, as influenced by Food, and by House Drainage.
}

THE following remarles relate to the causation and prevention of diseases, the object of all sanitary work. This kind of work is, we lnnow, of quite recent origin; some of us may have helped, in our day, to develop it; yet, long ago, before the work or its name was thouglit of, the progress of human improrement did something to banish diserse.

Thus, during the middle ages, leprosy was so common in the British Islands, that leper-hospitals were founded everywhere, and their sites are still known by the name 'Spital.' Leprosy receded and grew less common, according as improvements in agriculture and horticulture, and in the rearing of live stock, funished better, more regular, and more abundant supplies of food, both animal and vege- 
table. Fresh food began to be more easily obtained; it was less necessary to live upon salted or dried provisions. And as lyy degrees the art of food-producing became more perfect, leprosy disappeared; first from England, nfterwards from Ireland and Scotland ; lastly, from the Orkneys, Hebrides, and Shetlands, lingering longest precisely where the methods of raising abundant regular supplies of fresh food were least practised, and still causing cases of the disease among people who were unable to procure such nutriment. Very rarely, a case of leprosy in a person who has never been out of England still occurs. One such case is recorded by me in the 'Medical Times and Gazette,' for September 2, 1865, page 251. But the present rarity of leprosy, contrasted with its frequency in time past, forcibly reminds us of the value and importance of good, fresh food, in the maintenance of life and health, and in the prevention of disease.

A similar lesson is taught in the history of a small parish in Sussex. Fifty years ago, ague was prevalent there; but lately, and for some year's past, it has never been heard of. The disappearance of ague is usually attributed to the clraining and reclaiming of marshes; but there is no marsh in or anywhere near this parish, nor has any alteration been made in the surface of the land. But there has been a material change in the condition of the people. Their stanclard of living has been improved, both by the rise in wages and by the increased demand for clay-labourers. Fifty year's ago, men were frequently out of work there cluring the winter, and their families were almost without food; parish relief had to be given them, and landowners employed them in planting waste land. A riotous mob burnt a threshing machine in the parish, because 'it took the poor man's work away from him.' But now, side by sile with the introduction of all sorts of machinery into farm-work, it is very diflicult to obtain a labourer. I beliere the disappearance of ague in that parish, which is intimately known to me, is owing to the people being better fed thin they were fifty yen's ago, and therefore being unaffected by the slight malaria, which arises from woods and fields in most country places, which diluted malaria, when formerly the people were not so well fed, gave to a certain per centage of them ague. It is likely that the history of many English parishes would furnish similar instances.

Thus may, and does, good food keep off cisease, both ague and many other kinds, by so upholding the strength that well-fed persons exposed to deleterious influences are less frequently made ill by them. Proper food also banishes leprosy, scurvy, aud diseases of that stamp, in a way more direct, by improving the condition of the blood. Wellnourished people recover from illnesses, which carry off persons who are under-fed. These things point out to us the enormons value of extended and diversified meaus of abundint food supply, and of doing everything to chenpen good food, to bring it within reach of all, and to make generally known the best moles of preparing it. No sanitary measures can equal this. The food question stands first. The introduction of every new article of food; quiclier or more plentiful methods of raising food; the making two ears of coru grow where one only grew before; the teaching of cookery; improved ways of preserving food, of making it portable, and of transporting it ; and 
the establishment of food-museums in large towns; all these are a boon and benefit to mankind, and tend to banish pestilences and epidemics, and to minimise sickness and mortality. Feed a people well, and they can defy an astonishing number of sanitary errors. Diminish their food, no matter by what means, whether by scarcity, or by want of money to buy, or by indulgence in alcololic rlrinks or other matters that destroy appetite, and straightway they fall victims to the miasma from drains and cesspools and refuse-heaps, to want of ventilation, and to every other sinitary blunder.

I question if some of our supposed domestic improvements be not sanitary blunders. Every house must now have within it a place with water-pipes and machinery, which years ago were not needed in the small edifice at the end of the garden which then served the same purpose. These pipes communicate with driains, and are neither more nor less than conductors into our houses of poisonous gases, which our forefathers, with all their shortcomings, kept at arm's length. I repeat, they are conductor's of miasma into our houses; for, however well-constructed they may be, they cannot be always perfect; and every slight leaknge, every little derangement of valves and levers, every deficiency of water, and also the carelessness of those who use them, may and does occasion some ingress of bad emanations into our dwellings, the effects of which, in causing illness, every medical man of experience has observed. The same applies to indoor sinks. It is since these triumphs of the plumber's art have come into general use, that typhoid and diphtheria have been frequent in this country. Forty years ago these diseases were scarcely heard of. Typhoid was not known by name, though the resenrches of Broussais had pointed out a typhus-like ferer which yet differed from typhus. And though now and then cases of this typhoid, better named enteric fever, were met with, still at that date, even allowing for its not being always recognised, it was not nearly so frequent as at present. It is supposed by many tbat diphtheria was then unknown. It was certainly very uncommon; very few medical men had seen it; but of late years it is only too frequent. Now, the increased frequency of these two diseases manifestly accompanies the general introduction and use of water-closets within our houses, an arrangement well known to have caused diphtheria, typhoid, and other ilinesses in numerous instances, by some part of the apparatus getting out of order, and occasioning contamination either of the air or of the drinking-water. Obviously, there can be now no need to enumerate cases in proof. That it is so, will be conceded by all who are conversant with sanitary affairs; and those to whom the matter is not so clear can soon convince themselves by reference to recorded instances. But what I wish, in conclusion, to direct attention to, is the custom of late years adopted, of introducing into every house a tube which communicates with drains, and the prevalence of typhoid and diphtheria since this custom became general. Indoor closets should only be used when necessity compels; and the arrangements connected with then, which are generally very defective, should be wholly altered. Every such place should have two windows or apertures so as to cause a constant thorough draught through it, and should also be efficiently shut off 
from the rest of the house by a closely-fitting door. Till all these points are attended to, which they most certainly are not at present, preventable illness, of more or less serious character, will constantly occur.

And now, having mentioned in the first part of this paper the importance of augmenting our food supply in every direction, $\mathrm{I}$ will add a word on the- subject by way of appendix. Respecting animal food, what reason is there why our main supplies of meat, now so high in price, are to be derived only from the sheep, the ox, and the pig? With all our zoological information, can we think of no other animal, besides these three, that is adapted to furnish a meat supply for ordinary use? Because the experiment with elands, and with one or two others, failed, can nothing else be tried? It is easier to ask these questions than to answer them; yet that is no reason why something should not be done. The kingaroo, the wombat, many sorts of deer and aumals allied to them, the hison, the zebu, the camel, and others, furnish excellent food. We hear much of horseflesh; it is also said that the meat of donkeys and mules is good. It is a pity the reindeer cannot be utilised in England, for its flesh is excellent. Fish-culture, again, is yet in its infancy, and might be widely extended, and made to include the better sorts of shell-fish. Hundreds of tidal estunries now lie idle, which might be turned to some useful purpose in connection with this. Respecting vegetables, again, and cereals, it is astonishing, considering the hundreds of thousands of species in botanical lists, that so few linds are appealed to for human food. Small supplies of new descriptions might be oljtained from many plants now neglected; but the great gain wonld be if anything were discovered to add to our main crops, to stand side by side with whent or the potato. Having seen something of the Irish potato famine, the deserted villages and roofless cottages, the ground torn up around them to gather roots to boil for food, and the fields of good land lying waste which no one dare till or put stock on, I am cleeply impressed with the importance of not trusting to one or two species from which to raise food, but of putting in requisition as many kinds as possible, both of plants and animals, to furnish this first essential for the health of the people.

\section{W. E. C. NourSE, F.R.C.S.}

Mr. White (London) said he should like to ask a question with special reference to the village in Sussex, in which fifty years ago the people were subject to ague and such-like diseases. He was informed that these diseases had been in great measure remedied by the better provision made for the population. He should like to ask if it was not the case that there had been a material change in the structure of cottages in the ague districts of Kent and Essex. In the old days, when the cottages were almost exclusively on the ground, the absence of ague was never known; but as soon as the cottagers began to live eight, or even six feet above the ground, these symptoms disappeared. He should like also to know as to the soil, and whether its tenacity was such as to hold the water and throw off injurious exhalations. As an instance of the effect of sewer air, he mentioned the 
case of poisoning at Welbeck, where a number of persons mere poisoned by partaking of sandwiches made from a ham kept in a larder in which there was communication with a sewer.

Dr. TAYLon (Norwich) said he thought that per se sewer-gas was credited with more disease than it was accountible for. Berlin, as they knew, was a city of stinks, and during his residence in that place he believed that he had breathed more sewer-gas than anyone who resided in a more sanitary country. But on no occasion had he suffered from typhoid and other cliseases, which in this country were attributed to the action of sewer-gas per se. He had come to the conclusion that there was little evidence that impure water and air were capable of producing such disenses as was said. Whilst in Berlin his bedroom was surrounded by courts, in which were stables, wells, and closets; and the state of the atmosphere in his room was at times such that he could not see. He was also a rigid water drinker, but during his stay there, although he had drunk water uncloubtedly polluted, he never suffered from typhoid fever or other diseases attributed to sewer-poison.

Mr. Ciradwici said the statistics of Berlin were an answer to Dr. Tiylor. In going round the city they would find that the proportions of overcrowding and other conditions with the cleathrate corresponcled. The results of his examination of the statistics as to Berlin showed that the result was quite in accordance with what was met with everywhere, that insanitary conditions of living raised the death-rates and the prevalence of disease.

Mr. KARKEer expressed his surprise at hearing remarks which implied that sewer-gas and polluted water wele not dangerous. $\mathrm{He}$ was surprised at Dr. Taylor's remarks, pointing to Berlin as a sanitary city, as his own experience there had been quite the contrary.

The President said that Dr. Taylor did not say that sewer-gas was innocuous, but that he had lived in Berlin, had breathed sewergas and drunk polluted water, and was not affected.

Mr. Tow LE (Oxford) remarlied that in Berlin 28,000,000 gallons of water were every day pumped thirty-eight feet high, and flowed into the city. That must cause a lot of dirty water, which was conveyed miles away from the city. That was his system to a certain extent, but by his system they also got rid of the solids. If these 28,000,000 gallons of dirty water could be dispersed over the hills round London, and over the downs, what a benefit it would be! At present the country was being ruined by the sewage being sent into the sea.

Mr. Pencelery (Torquay) agreed that too much was attributed to impure air and water, and not enough to germs of disease, which were liable to be overlooked.

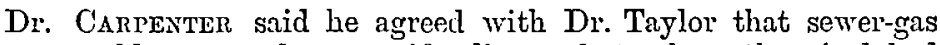

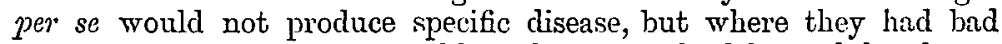
sewage arrangements they could not have pure health; and they knew that it was in the sewers that the germs of disease were created, and that where the gas went the germs went. If Dr. Taylor was not struck by them, so much the better for him. But in a similar way a man might be in a battle without being hit: the bullets would be 
none the less a fact, however. If they had no sewer-gas, there would be no vehicle by which these germs could be conveyed.

Mr. Nourse, in answer to the question as to the honses in Sussex, said that in 1844 or 1845 they were rebuilt, and tbat, and the better food which the people were able to obtain, had doubtless much to do with the altered state of things.

\section{Means of Prevention and Cure of Hydrophobia.}

The President announceil that Dr. Richardson had sent in a translation of a paper, by a French gentleman, on 'A Proposal of Measures for the Prevention of Hydrophobia.' This paper, by M. Decroix, was sent in French. The following is an abstract of the chief points. He starts by olsserving that every case, or nearly cver'y case, of madness in dogs can be traced to a bite from another dog. Starting from this principle, M. Jean Bourrel has proposed to prevent the disease by cutting or filing dogs' teeth in orcler to render it impossible for them to bite. Experiments were made by shutting up mad dogs with other dogs in cages, and allowing the former to bite the latter; the skins of which were found lacerated and pierced. The mad dogs then had their teeth filed and cut, and a similar experiment was made. Although the healthy dogs were attacked the skin was not broken. The writer further states that the process of filing and cutting the teeth is neither painful nor unsightly.

In the second part of the paper the writer upholds the tendency of the disense to proceed (at lenst sometimes) to spontaneous cure; and he recommends that both animals and men afflicted by it should be left alone, and not agitated with attempts at cure, or palliation. The only measure he recommends is the vapour bath. 